Supporting Information

\title{
Temperature and Strain Compensation for Flexible Sensors based on Thermosensation
}

Liangqi Wang, Rong Zhu*, and Guozhen Li

State Key Laboratory of Precision Measurement Technology and Instruments,

Department of Precision Instrument, Tsinghua University, Beijing 100084, China

*E-mail: zr_gloria@mail.tsinghua.edu.cn 


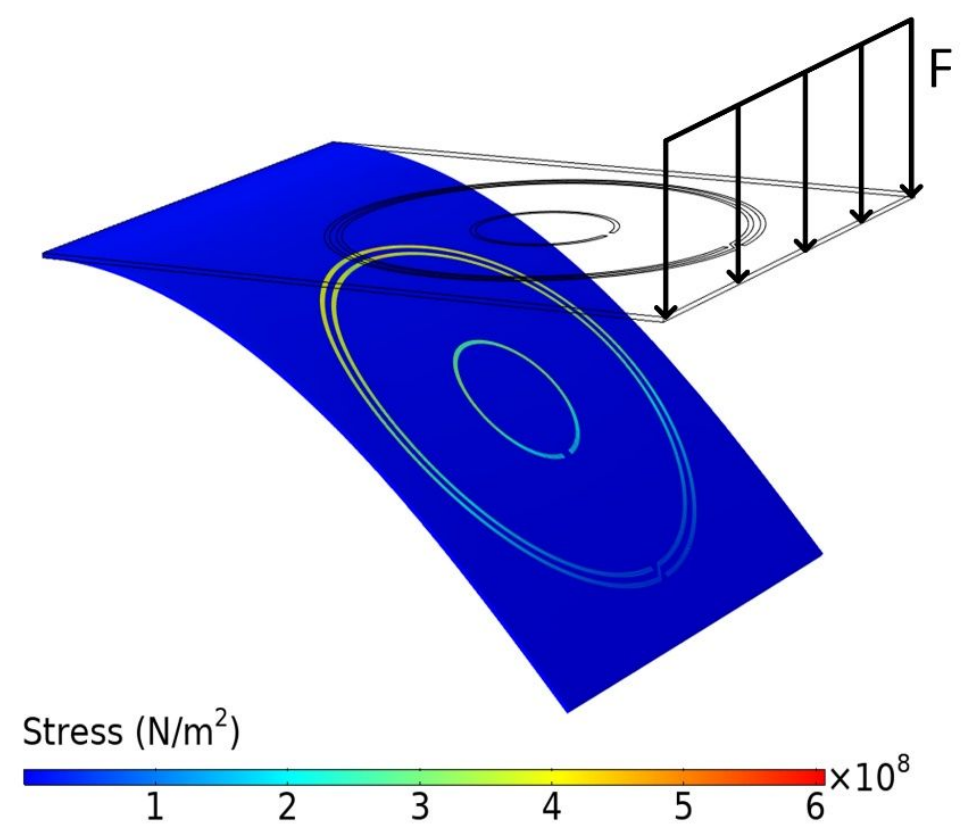

Figure S1. Simulation results. PI substrate is $1 \mathrm{~cm} \times 0.8 \mathrm{~cm} \times 60 \mu \mathrm{m}$. The radii of two concentric annular ribbons are $1 \mathrm{~mm}$ and $3 \mathrm{~mm}$ respectively, the widths of two ribbons are $75 \mu \mathrm{m}$, and the thicknesses are $100 \mathrm{~nm}$. Vertically downward load $\mathrm{F}$ is applied on the right edge while the left edge is fixed. Two ribbons experience strain and stress when the PI is bended by the load. The resistances of two ribbons are simulated by using Electronic Currents (ec) Physics of COMSOL. 

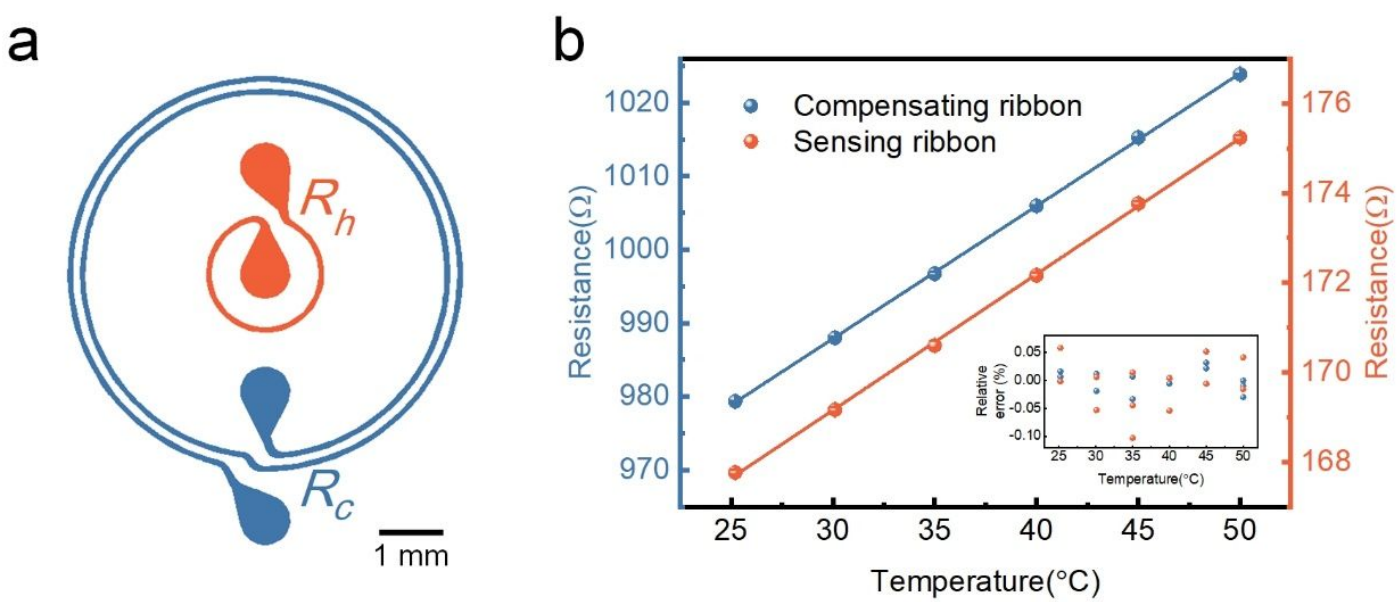

Figure S2. The layout of the sensor. (a) The width of the ribbons is $75 \mu \mathrm{m}$. The length ratio of the sensing ribbon $\left(R_{\mathrm{h}}\right)$ and the compensating ribbon $\left(R_{\mathrm{c}}\right)$ is about 1:6. (b) The resistance of $R_{\mathrm{c}}$ and $R_{\mathrm{h}}$ are about $168 \Omega$ and $979 \Omega$ at $25{ }^{\circ} \mathrm{C}$. The temperature coefficient of resistance (TCR) of a thermistor is defined as $\alpha=\Delta R /\left(R_{0} \times \Delta T\right)$, where $R_{0}$ is the resistance at $0^{\circ} \mathrm{C}, \Delta R$ refers to the resistance change when the temperature change is $\Delta T$. The TCRs of $R_{\mathrm{c}}$ and $R_{\mathrm{h}}$ are $1.933 \mathrm{ppm} \cdot \mathrm{K}^{-1}$ and $1.896 \mathrm{ppm} \cdot \mathrm{K}^{-1}$, respectively. 
a

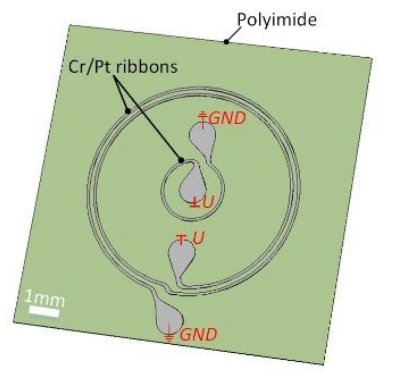

(i)

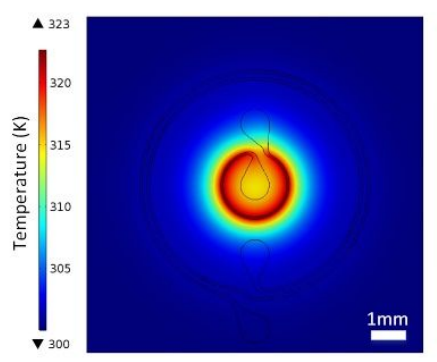

(ii)

b

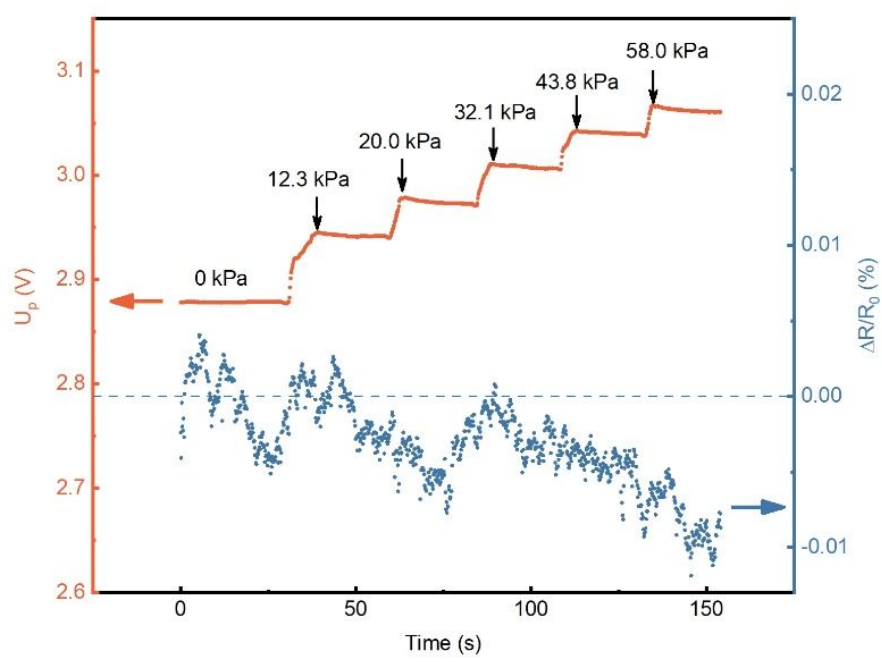

Figure S3. Thermal interference between hot film and cold film. (a) Electricalthermal simulation. (i) Illustration of the electrical-thermal simulation condition that applying an equal voltage onto the annular ribbon and center ribbon. (ii) The steady temperature distribution of the sensor. The center ribbon is electrically heated to a higher temperature, $20 \mathrm{~K}$ higher than ambient temperature ( $300 \mathrm{~K})$. Meanwhile the cold film is approximate at ambient temperature. (b) Experimentally measured outputs of the pressure sensor and cold film under different pressure stimuli. The output of cold film changes slightly $(<0.01 \%)$ when different pressure stimulus ranging from 0 to $58 \mathrm{kPa}$ is applied. 
a

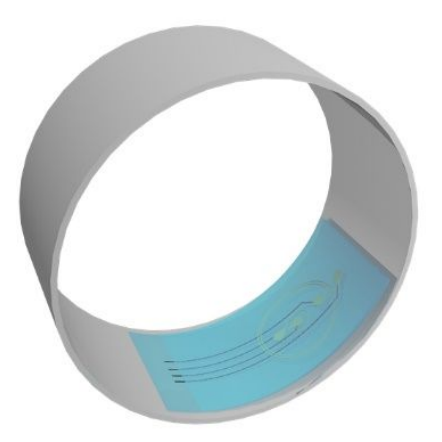

b

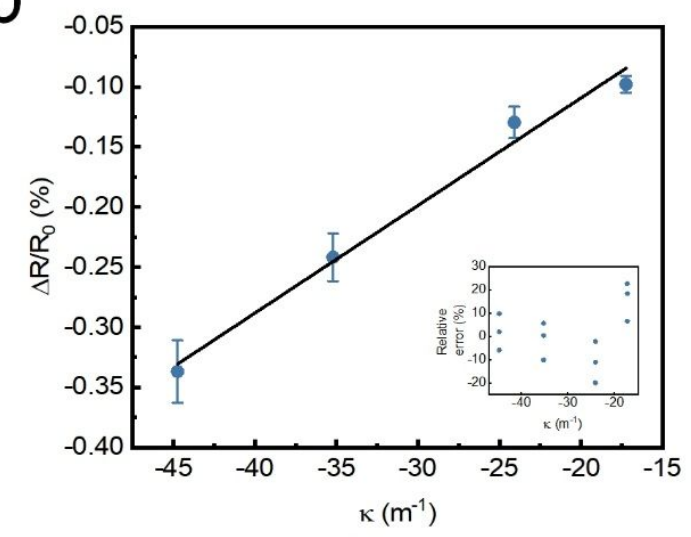

Figure S4. Characterization of curvature sensing when the sensor is compressed. (a) The compression bending set-up. (b) The relative resistance variation of the cold film under compression bending with different curvature. The solid line is fitted by using fitting method of linear least square. The inset shows the relative error. 

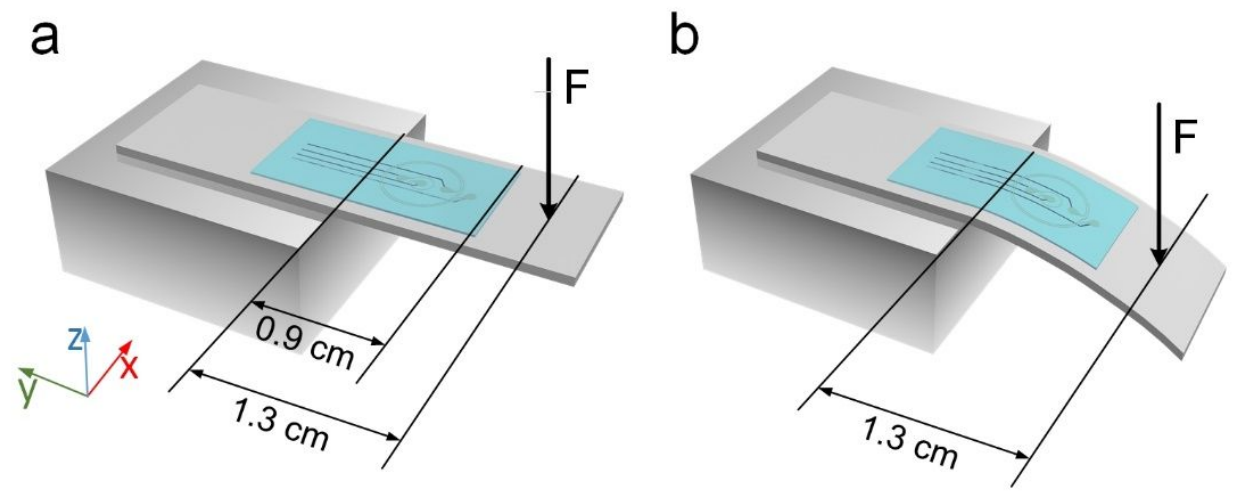

Figure S5. The sensor is attached on a cantilever beam to measure the bending displacement. (a) The location of force is $1.3 \mathrm{~cm}$ from the edge of the platform and the end of the PI substrate is $0.9 \mathrm{~cm}$ from the edge of the platform in y-axis direction. (b) The cantilever beam is bended under the vertical force along z-axis. The displacement in Figure $2 \mathrm{~g}$ is the vertical displacement of the force applied along z-axis. 
a

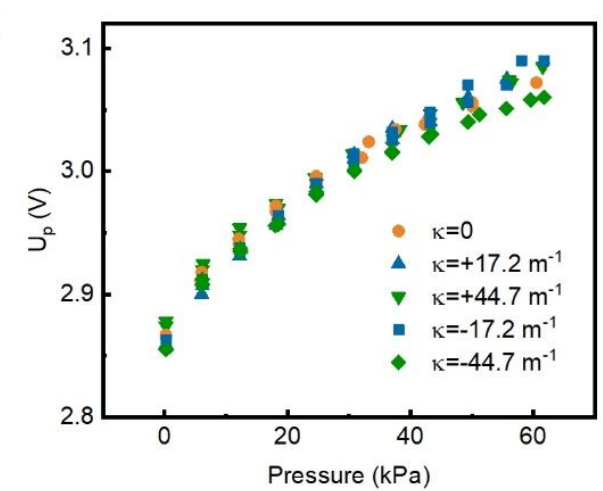

(i)

b

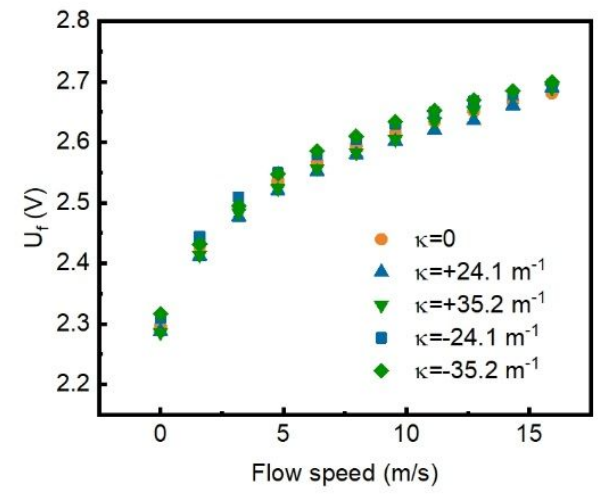

(i)

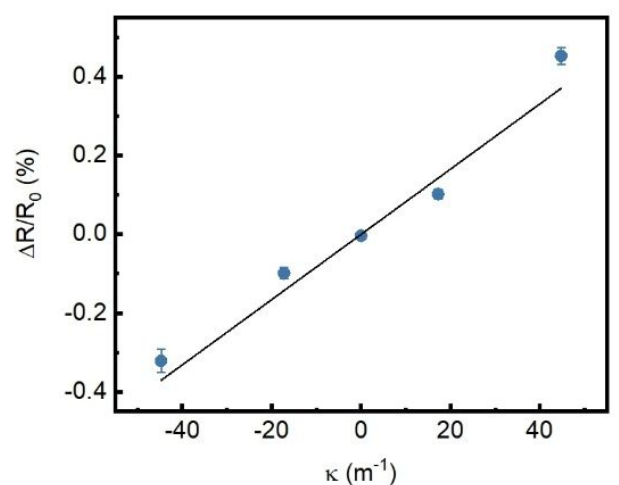

(ii)

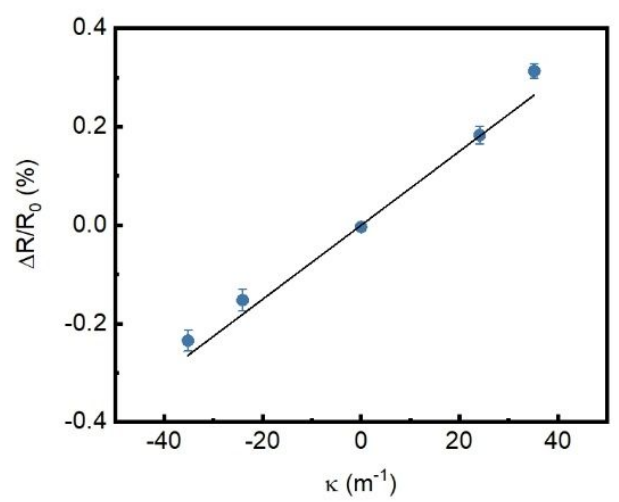

(ii)

Figure S6. Characterizations of pressure, flow speed and curvature sensing when the pressure sensor and flow speed sensor experience stretch and compression bending respectively. Positive curvature represents the sensor is under stretch, and negative curvature represents the sensor is under compression. (a) (i) Pressure responses under different curvature $\left(0, \pm 17.2 \mathrm{~m}^{-1}, \pm 44.7 \mathrm{~m}^{-1}\right)$. (ii) Curvature responses of the coldfilm under different curvature. (b) (i) Flow speed response under different curvature $\left(0, \pm 24.1 \mathrm{~m}^{-1}, \pm 35.2 \mathrm{~m}^{-1}\right)$. (ii) Curvature responses of the cold-film under different curvature. 

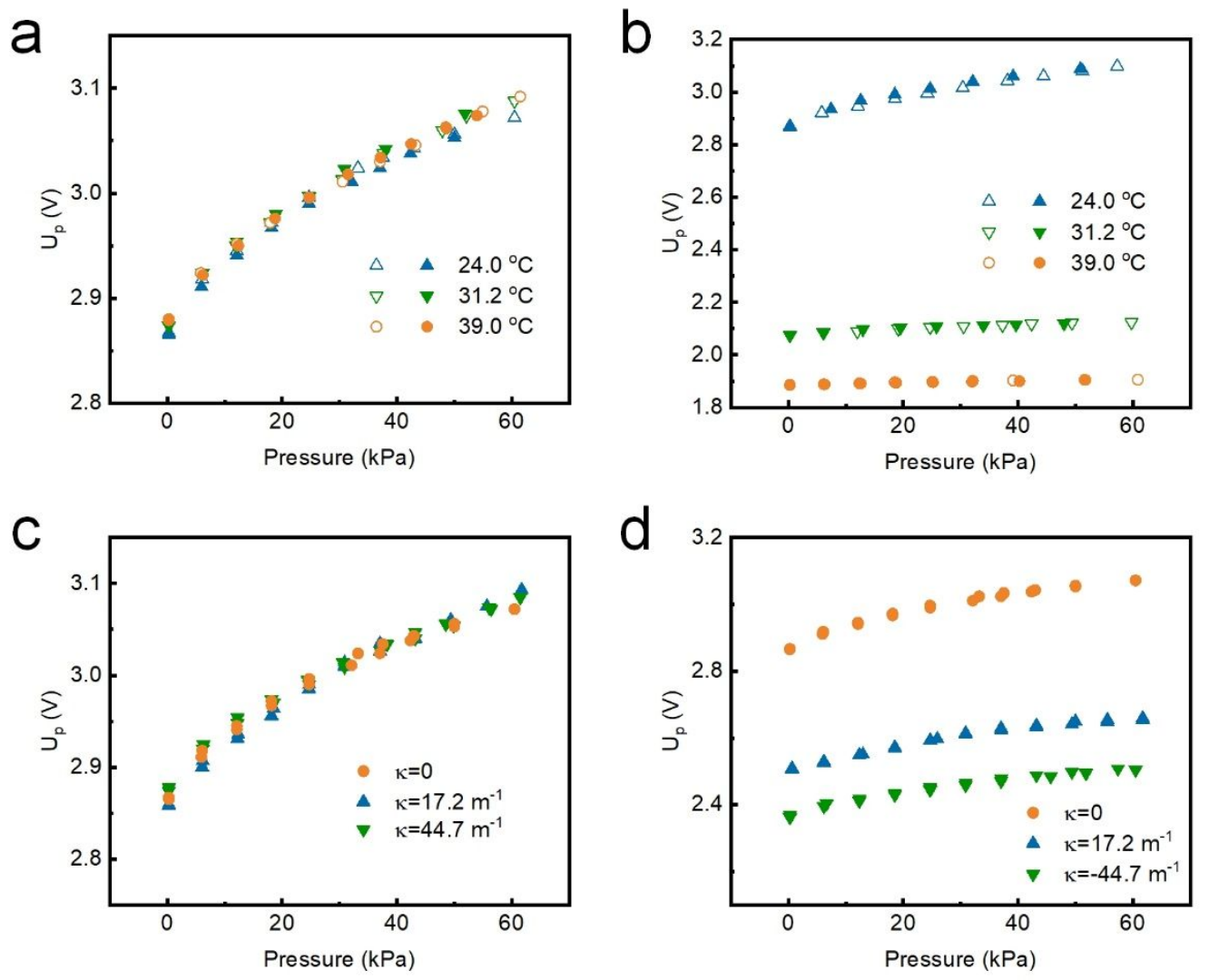

Figure S7. Pressure response of pressure sensor with and without compensation under different temperature and different bending curvature respectively. (a) Pressure response with compensation under different temperature $\left(24.0^{\circ} \mathrm{C}, 31.2^{\circ} \mathrm{C}\right.$ and $39.0{ }^{\circ} \mathrm{C}$ ). (b) Pressure response without compensation under different temperature ( $24.0^{\circ} \mathrm{C}, \quad 31.2^{\circ} \mathrm{C}$ and $39.0^{\circ} \mathrm{C}$ ). (c) Pressure response with compensation under different curvature $\left(0,17.2 \mathrm{~m}^{-1}\right.$ and $\left.44.7 \mathrm{~m}^{-1}\right)$. (d) Pressure response without compensation under different curvature $\left(0,17.2 \mathrm{~m}^{-1}\right.$ and $\left.44.7 \mathrm{~m}^{-1}\right)$. 

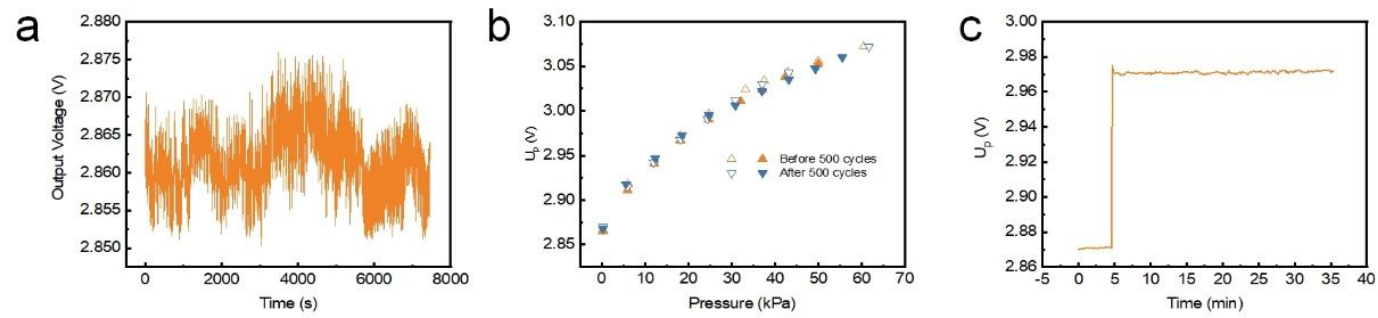

Figure S8. The sensor demonstrates good stability and durability. (a) Sensor response to periodical cantilever bending with amplitude of $15 \mathrm{~mm}$ for 500 cycles ( $14 \mathrm{~s}$ for each cycle, continues for about 2 hours). (b) Pressure responses of one consecutive loadingunloading measurements before and after 500 bending cycles. The pressure sensing performances before and after bending agree well with each other, which reveals the sensor has good durability. (c) Pressure response of $18.5 \mathrm{kPa}$ after 500 bending cycles. 